\title{
Temporalidade, envelhecimento e linguagens tecnológicas: educação e emancipação na contemporaneidade
}

\author{
Carla da Silva Santana Castro ${ }^{1}$ \\ Claudia da Silva Santana² \\ Marina Soares Bernardes ${ }^{3}$
}

\section{Resumo}

Este artigo discute as relações entre temporalidade, envelhecimento e linguagens tecnológicas, compreendendo que os processos de emancipação humana na contemporaneidade se articulam ao domínio e capacidade de comunicar e produzir linguagem em novas configurações e ambientes da cultura digital. Resultado de estudo teórico e revisão da literatura, o texto traz reflexões sobre a educação de idosos no cenário da cibercultura. Pressupõe o conhecimento da tecnologia como importante instrumento para a interação e comunicação do indivíduo idoso, bem como desempenhar tarefas cada vez mais complexas e vinculadas às tecnologias de informação e comunicação. $O$ papel da educação formal e não formal é analisado a fim de mostrar a relevância desses espaços para os processos de emancipação humana.

Palavras-chave: Temporalidade; Linguagens Tecnológicas; Educação; Emancipação Humana.

\section{Temporality, aging and technological languages: education and emancipation in contemporary world}

\begin{abstract}
This article discusses about the relations between temporality, aging and technological languages, understanding that the processes of human emancipation in contemporary world are articulated to the cibercultural domain and ability to communicate, express and produce language in new settings and environments of digital culture. Result of theoretical study and review of the literature, this paper brings reflections on the education of the older people in the scenario of cyberculture. It is assumed that knowledge of technology is an important instrument for the older individual to be able to interact, communicate and express himself, as well as perform increasingly complex tasks linked to the technologies of information and communication. The role of formal and non-formal education in the context of elderly education is analyzed in order to show the relevance of these environments for the processes of human emancipation.
\end{abstract}

Keywords: Temporality; Technological Languages; Education; Human Emancipation.

\section{Considerações iniciais}

O fenômeno do envelhecimento fez somar vários anos de vida à população mundial e estendeu o curso de desenvolvimento humano. Embora a longevidade sempre tenha sido uma das grandes aspirações da humanidade, atualmente, a sociedade experimenta os desafios e as

\footnotetext{
${ }^{1}$ Faculdade de Medicina de Ribeirão Preto da Universidade de São Paulo, Ribeirão Preto, carla.santana@fmrp.usp.br

2 Universidade Metodista de Piracicaba (UNIMEP), Piracicaba, santana50claudia@gmail.com

${ }^{3}$ Universidade de São Paulo, São Carlos, sbernardesmari@gmail.com
} 
oportunidades que a emergência desse grupo geracional traz com demandas concretas relacionadas à autonomia, participação social, cuidados, autorrealização e dignidade. $\mathrm{O}$ acesso e garantia aos direitos fundamentais de alimentação, habitação, saúde, trabalho, educação e previdência, para todos, se impõem na efetivação de políticas públicas, ao lado das dimensões do cuidado familiar ou institucional; da autorrealização que promova plenamente potenciais de desenvolvimento dessa população, possibilitando-lhe acesso a equipamentos culturais, educacionais e de lazer; da dignidade que deve assegurar proteção contra violência. Como viver bem essa longevidade e concretizar projetos de vida neste tempo com o qual muitos não contavam, ou não se apercebiam de sua iminente chegada, emerge como uma questão a ser debatida e enfrentada.

Nessa perspectiva, este artigo se propõe a refletir e discutir as relações entre temporalidade, envelhecimento e linguagens tecnológicas, apresentando-se como resultado de estudo teórico e revisão de literatura sobre a educação da pessoa idosa no cenário da cibercultura. Para tanto, buscou-se abranger reflexões e debates de autores estudiosos da questão da pessoa idosa, no contexto das principais legislações pertinentes, a Política Nacional do Idoso (1994) e o Estatuto do Idoso (2003), em articulação com as novas ambiências da cultura digital na contemporaneidade.

Assim, no contexto deste debate observa-se que a longevidade carrega consigo um paradoxo frente ao desejo do ser humano de prolongamento do seu tempo de vida: acrescentam-se anos à expectativa de viver mais para um ser que envelhece. A longevidade não se apresenta como permanência de uma juventude inesgotável, no entanto, sinaliza a possibilidade de se viver significativa parte do tempo de vida na condição de envelhecimento. Ao mesmo tempo em que é concebida como um processo natural e biológico, a velhice é também um processo bio-psico-social, uma construção social e cultural, repleta de significações. Caracterizar a velhice não é, portanto, tarefa simples, como advertem Marques e Pachane (2010, p. 478), uma vez que "ela não consiste somente em um estado, mas sim em constante e sempre inacabado processo de subjetivação. Assim, na maioria das vezes, podemos dizer que não existe um 'velho', mas sim um 'ser envelhecendo'".

A questão etária tem sido determinante para a formulação de políticas públicas, seja para estabelecer a organização de sistemas escolares e idade de ingresso na educação infantil ou no 
ensino fundamental, seja para definir a época e condições para ingresso em benefícios como aposentadoria (CAMARANO, 2016). Trata-se de parâmetro que oferece balizas para normas sociais, definindo o que se encontra dentro ou fora da classificação.

As chamadas idades da vida e suas respectivas passagens são marcadas por representações sociais, projetando expectativas de comportamentos e modos de ser. Beauvoir discute a velhice na perspectiva de sua visibilidade no campo social, argumentando:

Enfim, a sociedade destina ao velho seu lugar e seu papel levando em conta sua idiossincrasia individual: sua impotência, sua experiência; reciprocamente, o indivíduo é condicionado pela atitude prática e ideológica da sociedade a seu respeito. De modo que, uma descrição analítica dos diversos aspectos da velhice não pode ser suficiente: cada um deles reage sobre todos os outros e é por eles afetado. É o movimento indefinido desta circularidade que temos de aprendêla (BEAUVOIR, 2018, p.13-14).

Considerando a necessidade de olhar a velhice a partir de uma visão de totalidade, faz-se necessário evidenciá-la inserida em um contexto sócio-histórico com suas múltiplas relações políticas, econômicas, culturais, sociais e educacionais, conjuntamente com fatores biológicos. Esse olhar holístico permite ver e desvelar rupturas, transformações e continuidades na representação da pessoa idosa que irá implicar na maneira como a sociedade impõe seu lugar e papel social.

Marques e Pachane (2010, p.478) apontam para filtros sob os quais a sociedade constrói imagens de pessoas idosas, sinalizando a valoração que a sociedade capitalista atribui para a capacidade de produção e retorno econômico.

A sociedade determina, segundo interesses convencionados, o lugar e o papel do idoso. O critério de idade não é o único usado por ela, mas reúne em si justificativas para a não valoração e não emancipação desse ator social. Tais justificativas atrelam-se aos arranjos sociais elaborados pela lógica do capital e seu centro de interesses, pautado pela produtividade e retorno econômico, que descartam aqueles que estão à margem desse quadro, entre eles, os idosos.

Em um contexto de profunda desigualdade social como no Brasil, apresentam-se distintas e variadas condições sociais de pessoas idosas, com distribuição desigual de benefícios advindos dos avanços tecnológicos. Nesse sentido, o aumento da população idosa se constitui um desafio, 
originando um conjunto de demandas que requerem respostas, planejamento e estabelecimento de estratégias para que as políticas e legislações já aprovadas se efetivem.

Os dados demográficos indicam um cenário futuro preocupante se não nos prepararmos para as exigências que se farão sentir, em um curto período, nos diversos níveis e segmentos da sociedade e de suas instituições. Nos próximos dez anos, um bilhão de idosos serão somados à população mundial. ${ }^{4}$ Segundo o Instituto Brasileiro de Geografia e Estatística - IBGE (2019), no Brasil a população idosa irá triplicar em quarenta anos, passando de dezenove milhões e seiscentos mil para sessenta e seis milhões e quinhentos mil idosos. A inversão do perfil demográfico deverá acontecer na terceira década do milênio, quando o número de pessoas com sessenta anos ou mais será maior do que o número de crianças de zero a quatorze anos de idade. Esses dados reforçam o reconhecimento de que o século XXI é, muito provavelmente, o século das pessoas mais velhas.

Ao lado do desafio que se constitui a emergência desse grupo etário, será preciso considerar a oportunidade que se abre para firmar novas políticas, instituições e práticas sociais na saúde, educação, habitação, economia, dentre outras áreas. A mudança demográfica que se anuncia provoca a capacidade de lidar com situações inéditas e, dessa forma, gerar novos modelos e estratégias inclusivas que pavimentam uma estrada que todos devemos trilhar.

Assim, dentre os inúmeros desafios e oportunidades, dispostos em um cenário de intensas e velozes mudanças sociais, este texto se propõe a refletir e discutir as relações entre temporalidade, envelhecimento e linguagens tecnológicas, entendendo que os processos de emancipação humana na contemporaneidade se articulam ao domínio e capacidade de comunicar, expressar e produzir linguagem em novas configurações e plataformas digitais. Partese do pressuposto de que o conhecimento da tecnologia se faz importante para que o indivíduo idoso consiga interagir, comunicar-se e expressar-se, bem como desempenhar tarefas cada vez mais complexas e vinculadas às tecnologias de informação e comunicação, como utilizar bancos on-line, caixas eletrônicos, assim como dominar o novo jargão tecnológico: o do código de barras, $Q R$ Code, do e-mail, mensagens instantâneas do tipo WhatsApp, das siglas, símbolos e ícones, e de todo o discurso com que se compõe o universo das redes sociais: compartilhar,

\footnotetext{
${ }^{4}$ In: UNFPA, Fundo de População das Nações Unidas e HelpAge Internacional. Envelhecimento no Século XXI: Celebração e Desafio. Nova York, e pela HelpAge International, Londres, 2012.
}

Periódico Horizontes - USF - Itatiba, SP - Brasil - e020045 
encaminhar, salvar a tela, adicionar etc. O desenvolvimento de competências e novas habilidades para se viver em uma sociedade tecnológica, apropriando-se e dominando novas linguagens pode se constituir em um importante instrumento de emancipação na sociedade contemporânea.

Para Merleau-Ponty (1971), o tempo nasce da nossa relação com as coisas que nos rodeiam, que fazem parte de nossa vida cotidiana. Assim, os desafios contemporâneos, ao mesmo tempo em que nos mostram um mundo tecnológico aparentemente ameaçador, no qual muitos idosos não se percebem fazendo parte dele, também pode se revelar promissor, quando estimula o desenvolvimento de novas competências e habilidades e possibilita a integração das tecnologias digitais no cotidiano das pessoas idosas, gerando a percepção de pertencimento e a capacidade para lidar com as transformações advindas dos avanços da tecnologia. Trata-se da abertura de uma janela de oportunidades com potência para importantes mudanças, com inclusão e emancipação social.

\section{Cultura digital e a dimensão dos processos de inclusão e emancipação}

Cidadãos idosos têm expectativas crescentes em termos de inclusão plena na sociedade, na cultura e na economia, com qualidade de vida e exercício de direitos, bem como resgate de condições para seu reconhecimento social e relações familiares e sociais significativas. A inclusão plena da população idosa na cultura digital, como usuário e produtor, poderá permitir a manutenção de seus papéis sociais e ocupacionais, dispor ferramentas para o exercício de cidadania, da autonomia e possibilitar acesso ao centro de uma sociedade dinâmica e complexa, principalmente em virtude da capacidade de se obter informação e utilizá-la em seu favor no que diz respeito à cidadania e sua participação social. Entretanto, é preciso refletir sobre as condições concretas para a inclusão digital diante das profundas desigualdades sociais e distintas condições de acesso das populações que caracterizam o universo de pessoas idosas no país.

Ainda que tomemos como pressuposto a integração da tecnologia digital na vida da maior parte das pessoas, e de que estas foram se modificando ao longo do tempo na medida em que os processos de inovação e desenvolvimento tecnológico foram ocorrendo, há que se olhar para os sujeitos idosos, em diferentes classes sociais, como aqueles que têm sofrido concretamente 
o impacto dessas mudanças rápidas e inexoráveis, cujo potencial variável de exclusão social contribuiria para elevar níveis de segregação geracional e dificuldades de acesso aos bens culturais a essa população, sobretudo aos idosos pertencentes às camadas economicamente desfavorecidas da sociedade.

De acordo com Raymundo e Santana (2015), os constantes avanços na área de tecnologia e comunicação teriam sido positivos para a sociedade em vários aspectos. Se por um lado, porém, esses avanços representam uma pretensa facilidade de acesso aos recursos tecnológicos, por outro impõem um aumento da complexidade e consequente dificuldade para adaptação ao novo por parte de indivíduos pouco familiarizados com o mundo digital. É possível perceber que a parcela da população que mais apresenta dificuldades em se habituar a essas novidades é a idosa, justificadas pela inserção tardia desses dispositivos na vida desses sujeitos, quando os mesmos já eram adultos mais velhos ou mesmo idosos, podendo esta dificuldade mostrar-se ainda mais intensa a depender das condições concretas de acesso a esse universo, como já mencionado. Assim, o domínio das tecnologias digitais e de suas linguagens ainda não se constitui uma realidade para considerável parte da população de pessoas idosas que demonstra dificuldades para o uso pleno e compreensão de como estes equipamentos multitarefas funcionam, especialmente os aparelhos celulares, acarretando, potencialmente, a exclusão digital.

Esses equipamentos digitais com interface muitas vezes complexas e de difícil manejo estão fortemente integrados nas principais atividades instrumentais da vida diária, tais como o gerenciamento financeiro (que requer o uso dos caixas eletrônicos para as operações bancárias locais ou on-line como no internet banking, para a realização de compras em lojas físicas ou on-line, o manejo de senhas e códigos, cartões magnéticos e leitores digitais etc.); o gerenciamento e monitoramento de dados de saúde (que incluem equipamentos digitais como o glicosímetro para a verificação dos índices glicêmicos e o monitor de pressão digital, dentre outros); o estabelecimento e gerenciamento do lar que inclui a contratação de serviços, o manejo de equipamentos com interfaces digitais que vão desde os alarmes das casas aos aparelhos, tais como Blueray, as smart televisions com múltiplas funções, controles de voz e movimentos, controles remotos complexos com botões escritos em idioma inglês, TV a cabo etc.). 
A baixa capacidade de interação no universo da cultura digital, desde dificuldades para utilização de tecnologias, até a falta de domínio da linguagem com habilidades para editar e produzir conteúdo em redes digitais, pode comprometer a autonomia dos sujeitos idosos, gerando dependência e alijando esses sujeitos de uma interação profícua com os demais atores sociais e seu contexto. Para além dos aspectos relacionados a usabilidade de equipamentos, que por si já pressupõe disponibilidade desses e preparo de pessoas para facilitar seu uso, há o entendimento de que estamos a tratar de linguagens a serem dominadas e apropriadas por esses sujeitos sociais em uma cultura crescentemente digital e que, portanto, demandam a formulação e efetivação de políticas públicas sociais que garantam os preceitos legais.

A educação de pessoas idosas para a cultura digital pode ser concebida como instrumento de qualificação social, visando elevar a qualidade de vida e incentivar as atividades cognitivas, motoras, familiares e sociais das pessoas mais velhas. Ser proficiente nas linguagens e ter domínio sobre equipamentos digitais pode exercer grande influência no sentimento de pertencimento ao tempo contemporâneo tão largamente marcado pelas novas tecnologias. A inclusão digital é um preditor de independência e autonomia, principalmente na perspectiva do acesso à informação e velocidade com que estas alcançam o indivíduo, e adicionalmente se pensarmos que a conectividade coloca os indivíduos em contato com outros diminuindo o isolamento, ou ainda na perspectiva do uso de equipamentos que reduzem dificuldades cotidianas como as tecnologias assistivas, por exemplo.

Nessa perspectiva, identifica-se uma demanda para a educação relacionada à emancipação e autonomia de sujeitos idosos no contexto do desenvolvimento das tecnologias digitais no mundo contemporâneo, qual seja a de políticas e programas de educação formal e não formal que favoreçam a inserção dessa população neste universo e sua apropriação dos códigos e linguagens digitais. Trata-se de conceber tempos e espaços de ensino e aprendizagem, materiais didático-pedagógicos, bem como conhecimentos sobre as diferentes formas de aprendizagem de pessoas mais velhas. A maneira como esse grupo geracional aprende e processa novas informações, merece destaque ao se pensar sobre educação de idosos.

A ideia de educação de idosos no contexto da longevidade pressupõe identificar problemas e obstáculos e encaminhar soluções para a efetiva inclusão das pessoas idosas em um mundo imerso na cultura digital, possibilitando sua inserção e expressão nesta cultura. Para 
tanto, compreende-se a necessidade de programas e projetos com foco na formação para as linguagens e tecnologias digitais, dando efetividade às políticas públicas sociais já aprovadas em forma de leis. Movimentos como estes implicam em importantes questões como, por exemplo, a formação de professores para o desenvolvimento de projetos pedagógicos voltados para o ensino de idosos, dentre outros.

Os processos de emancipação pressupõem resistência e luta por condições dignas de vida e cidadania, e pressionam pelo desenvolvimento e implementação de políticas sociais para a vida plena das pessoas idosas. Nessa direção, a educação dessas pessoas se coloca como relevante agenda na promoção do valor e do respeito pelos idosos em nossa sociedade.

\section{Educação de idosos na ambiência da cultura digital}

Dentre as mais importantes legislações que tratam da questão do idoso, destacamos a Política Nacional do Idoso (PNI) ${ }^{5}$ aprovada no ano de 1994. A criação de condições para a promoção da "autonomia, integração e participação efetiva na sociedade" (BRASIL, 1994, art. 10), foi considerado um passo decisivo para a garantia de direitos à pessoa idosa. Ao longo de mais de vinte anos, desde sua aprovação, observa-se, conforme Camarano (2016), a intensificação das demandas por políticas públicas, a necessidade de atualização e implementação de medidas já estabelecidas naquele documento. 0 imperativo de se atentar para novas questões, ao mesmo tempo em que se procede uma análise sobre o cumprimento dos preceitos legais estabelecidos pela PNI, se impõe quando nos confrontamos com a aceleração do processo de envelhecimento no Brasil.

A PNI dá visibilidade à relação do Estado com as pessoas idosas, definindo quem é o idoso, quais princípios e diretrizes norteiam a ação social dirigida, as atribuições e responsabilidades sobre a organização e gestão da Política; as ações governamentais para sua implementação nas áreas de promoção e assistência social, saúde, educação, trabalho e previdência social, habitação e urbanismo, justiça, cultura, esporte e lazer. Especificamente no que se refere à educação, a Lei no 8.842 (BRASIL, 1994) estabelece no item III, art. 10 do capítulo IV:

\footnotetext{
${ }^{5}$ Política Nacional do Idoso (PNI), Lei no 8.842/1994, regulamentada pelo Decreto n 1.948/1996.
} 
a) adequar currículos, metodologias e material didático aos programas educacionais destinados ao idoso;

b) inserir nos currículos mínimos, nos diversos níveis do ensino formal, conteúdos voltados para o processo de envelhecimento, de forma a eliminar preconceitos e a produzir conhecimentos sobre o assunto;

c) incluir a Gerontologia e a Geriatria como disciplinas curriculares nos cursos superiores;

d) desenvolver programas educativos, especialmente nos meios de comunicação, a fim de informar a população sobre o processo de envelhecimento;

e) desenvolver programas que adotem modalidades de ensino à distância, adequados às condições do idoso;

f) apoiar a criação de universidade aberta para a terceira idade, como meio de universalizar o acesso às diferentes formas do saber;

Destacam-se nessas diretrizes, a educação formal na modalidade Educação de Jovens, Adultos e Idosos - EJA; a educação não formal, remetendo ao formato das Universidade Aberta para a Terceira Idade - UNATIs e Universidade Aberta da Maturidade - UAM. Assim, contemplando a temática da cultura digital, abordada neste artigo científico, as menções para a educação a distância e para programas educativos nos meios de comunicação chamam a atenção, considerando a inserção requerida desses atores sociais na cultura digital e a necessidade de domínio de suas ferramentas.

Outro documento que trata da questão do idoso no conjunto de legislações brasileiras é o Estatuto do Idoso, a que se refere a Lei n.10.741/2003. Sua finalidade consiste em regular os direitos assegurados às pessoas com idade igual ou superior a sessenta anos. Composto por duzentos e trinta artigos, o Estatuto do Idoso abrange os aspectos saúde, transporte coletivo, violência e abandono, entidades de atendimento ao idoso, trabalho, habitação, lazer, cultura e esporte.

Com intuito de verificar como essa legislação estabelece diretrizes para a educação de idosos e define os âmbitos de sua realização, conteúdos e formas, interessa observar o que diz o Estatuto do Idoso em seu Título II, Dos Direitos Fundamentais, em seu Capítulo V, Da Educação, Cultura, Esporte e Lazer:

Art. 20. O idoso tem direito a educação, cultura, esporte, lazer, diversões, espetáculos, produtos e serviços que respeitem sua peculiar condição de idade. Art. 21. O Poder Público criará oportunidades de acesso do idoso à educação, adequando currículos, metodologias e material didático aos programas 
educacionais a ele destinados.

$\S 1$ 1 Os cursos especiais para idosos incluirão conteúdo relativo às técnicas de comunicação, computação e demais avanços tecnológicos, para sua integração à vida moderna.

§ 2으 Os idosos participarão das comemorações de caráter cívico ou cultural, para transmissão de conhecimentos e vivências às demais gerações, no sentido da preservação da memória e da identidade culturais.

Art. 22. Nos currículos mínimos dos diversos níveis de ensino formal serão inseridos conteúdos voltados ao processo de envelhecimento, ao respeito e à valorização do idoso, de forma a eliminar o preconceito e a produzir conhecimentos sobre a matéria.

Art. 23. A participação dos idosos em atividades culturais e de lazer será proporcionada mediante descontos de pelo menos $50 \%$ (cinquenta por cento) nos ingressos para eventos artísticos, culturais, esportivos e de lazer, bem como o acesso preferencial aos respectivos locais.

Art. 24. Os meios de comunicação manterão espaços ou horários especiais voltados aos idosos, com finalidade informativa, educativa, artística e cultural, e ao público sobre o processo de envelhecimento.

Art. 25. As instituições de educação superior ofertarão às pessoas idosas, na perspectiva da educação ao longo da vida, cursos e programas de extensão, presenciais ou a distância, constituídos por atividades formais e não formais.

Parágrafo único. O poder público apoiará a criação de universidade aberta para as pessoas idosas e incentivará a publicação de livros e periódicos, de conteúdo e padrão editorial adequados ao idoso, que facilitem a leitura, considerada a natural redução da capacidade visual (BRASIL, 2003).

Destacam-se nesta análise, o artigo vinte e um e seu parágrafo primeiro, que estabelecerá a responsabilidade do Poder Público na criação de acesso do idoso à educação, adequação de currículos, metodologias e materiais didáticos, assim como remeterá aos cursos especiais, neste caso a modalidade EJA, o encargo por incluir conteúdo relacionado às "técnicas de comunicação, computação e demais avanços tecnológicos, para sua integração à vida moderna" (BRASIL, 2003). Ou seja, o que está sendo chamado de inclusão digital na educação formal já figurava dentre as questões tratadas pelo Estatuto do Idoso há quase duas décadas no Brasil.

$\mathrm{O}$ artigo vinte e cinco e seu parágrafo único, estabelece o apoio do Poder Público para a criação de universidade aberta para pessoas idosas, ensejando programas em instituições de ensino superior públicas e privadas.

Cachioni e Todaro (2016) refletem sobre as intenções direcionadas à educação formal para idosos, constantes das políticas relacionadas a esse grupo, identificando as dificuldades para a implantação de currículos, metodologias e materiais didáticos adequados aos programas educacionais que atendem aos idosos. No âmbito da educação formal, a modalidade EJA que

$$
\text { Periódico Horizontes - USF - Itatiba, SP - Brasil - e020045 }
$$


passa a incluir o idoso, atende a população com baixa escolaridade, lidando com elevada heterogeneidade de perfis entre os estudantes. Especificamente sobre os alunos idosos que frequentam as classes de EJA, as autoras ressaltam:

... um perfil próprio que exige uma atuação dialógica, afetiva, sistematizada, pautada em pressupostos teóricos que consigam dar conta da sua singularidade histórica. Os alunos idosos da EJA são sujeitos da experiência e suas vidas são pontuadas por situações-limite em que souberam parar, pensar, sentir, ponderar e agir. Ao ir/voltar para a escola, querem viver essa experiência escolar como as outras já vividas ao longo de suas existências (CACHIONI; TODARO, 2016, p.178).

A questão preocupante não diz respeito à heterogeneidade em si, mas a necessidade de conhecimentos específicos sobre este grupo etário. A adequação de currículos, metodologias e materiais didáticos está diretamente relacionada ao conhecimento sobre o educando, de suas necessidades e expectativas e, neste caso, lidar com as diversas faixas etárias e especificidades culturais dentro da EJA adensa a complexidade da tarefa docente.

Todavia, é preciso lembrar, neste contexto, da relevância da formação inicial e contínua de professores e da necessária estrutura de apoio requerida para este trabalho na EJA, visto que a educação em viés intergeracional pode também vir a ser potencializada com as devidas condições neste âmbito, especialmente ao se objetivar garantir acesso e domínio das linguagens digitais aos idosos na educação formal, como preconizam a PNI e o Estatuto do Idoso.

Concernente à educação não formal, o olhar se dirige aos programas conhecidos como Universidade Aberta para a Terceira Idade - UNATIs e Universidade Aberta da Maturidade UAM, desenvolvido por diversas instituições de ensino superior. Diferentemente da educação formal, a modalidade não visa profissionalização ou certificação, convergindo para atividades relacionadas à socialização, partilha de experiências de vida, cursos livres, oficinas etc. Pressupõe-se a abertura para um mundo de saberes que a universidade poderá contribuir com seu ambiente multidisciplinar e intergeracional. Nessa direção, caracteriza-se em um espaço propício para o desenvolvimento de competências ligadas à cultura digital.

Em uma outra vertente educacional, Ferrigno (2016) chama a atenção para a importância da educação informal que ocorre no cotidiano das famílias e comunidades, assim como para o potencial da coeducação entre gerações. O autor destaca que tanto os idosos 
quanto os jovens têm contribuições na educação mútua. Por um lado, os idosos trazem suas experiências, memórias, tradições e, ainda, a rememoração do que se perdeu e dos que já partiram. São potenciais agentes de preservação da memória cultural. Em relação ao jovem, Ferrigno aponta contribuições vinculadas à vivência cotidiana, assim como outras partilhas, anseios e esperanças.

\footnotetext{
Um auxílio importante é a atualização de conhecimentos, mormente aqueles que dizem respeito a novas tecnologias diretamente relacionadas ao dia a dia. Além desses saberes, o convívio com gente mais moça propicia aos velhos a oportunidade de reverem seus conceitos sobre a juventude e seu estilo de vida, de modo a torná-los mais compreensivos em relação a temas sensíveis como sexualidade, drogas e os novos comportamentos da juventude (FERRIGNO, 2016, p.218).
}

São trocas potentes na educação, as quais direcionam a pensar sua viabilização em distintos espaços sociais. A intergeracionalidade remete ao pensamento de Paulo Freire (2019, p.25) na assertiva: "Quem ensina aprende ao ensinar e quem aprende ensina ao aprender". Nessa perspectiva, o idoso pode ser mestre e aluno das novas gerações, como aponta a reflexão de Ferrigno.

Na ambiência da cultura digital, os espaços de educação formal, não formal e informal desempenham papel relevante na educação de idosos, pois diferentes formatos podem ser mobilizados e projetados para dar conta de importante tarefa no desenvolvimento pleno do potencial das pessoas que seguem avançando na experiência do viver.

\section{Temporal discounting — inaugurando o tempo do desejo}

Os anos adicionais de vida, advindos com o fenômeno da longevidade, fez com que a velhice se tornasse uma das fases mais longas do desenvolvimento humano a qual iremos vivenciar. Esse fato implica na abertura de múltiplas possibilidades para a realização de projetos e desejos não concretizados em virtude das inúmeras demandas da vida adulta e que se modificaram ao longo do tempo, permitindo novas oportunidades na velhice.

Viveremos mais e quiçá vivamos melhor e com mais qualidade de vida, pois acrescer anos a mais à vida das pessoas faz sentido se estes puderem ser vividos com mais plenitude. De acordo 
com o IBGE (2019), uma pessoa nascida no Brasil em 2018 tinha expectativa de viver, em média, até os 76,3 anos. A expectativa de vida dos homens aumentou de 72,5 anos em 2017 para 72,8 anos em 2018, enquanto a das mulheres foi de 79,6 para 79,9 anos. Expectativa de vida aumentou 30,8 anos entre 1940 e 2018. Sendo que a expectativa de vida dos idosos aumentou em 8,2 anos de 1940 a 2018. O bônus da longevidade trouxe a possibilidade do temporal discount, que poderia ser compreendido como desconto do tempo, ou popularmente entendido como "correr atrás do tempo perdido".

O desconto temporal engendra o tempo do desejo e do desenvolvimento dos projetos de vida que, por algum descaminho no processo de desenvolvimento do indivíduo, não pôde se realizar, ou teve que esperar. Projetos de vida que são construídos paulatinamente no decorrer da existência das pessoas, mas que vão se modificando, se sincronizando à medida que encontram tempo e possibilidades de se concretizarem. Nessa perspectiva, a velhice se mostraria como o tempo do desejo e dos projetos que podem efetivamente sair da gaveta, quando esse indivíduo é convidado a repensar seu papel no mundo como sujeito autônomo, senhor de seu dizer e de suas ações.

$\mathrm{Na}$ vida adulta muitas situações podem impedir ou fazer adiar os planos pessoais, tais como o trabalho, cuidado dos filhos, cuidados com a casa, urgências financeiras, mudanças de prioridades, efeitos de uma destituição subjetiva (com perda de voz ou vez na velhice) etc. Nessa faixa etária, geralmente uma pessoa teria cumprido essas responsabilidades e faria jus ao direito da aposentadoria, o que Ihe permitiria um pouco mais de tempo livre para ser, idealmente, desfrutado da maneira que melhor lhe conviesse. Certamente, ao se falar em projetos de vida há que se considerar distintas realidades vivenciadas pelas pessoas idosas em um país como o Brasil.

Todavia, o contexto de longevidade anuncia o prolongamento de anos de vida que podem oferecer a chance de se pôr em prática projetos que ficaram guardados por muito tempo, não fosse a dificuldade em encontrar ambiência, recursos e serviços adequados a tais demandas. Mudanças demográficas e cenários socioeconômicos estão criando a necessidade de que profissionais e pesquisadores de diferentes áreas se conectem e busquem soluções com foco no envelhecimento da população, oferecendo produtos tecnológicos e serviços que atendam às suas necessidades e desejos (WOOLRYCH, 2016), sobretudo em países desenvolvidos. 
Os idosos, sujeitos da pesquisa de Santana, Bernardes e Molina (2016), foram questionados sobre os projetos de vida para curto, médio e longo prazo; e, em relação à educação, mostraram interesse em ampliar seus conhecimentos sobre a cultura de diferentes sociedades, aprender diferentes idiomas, instrumentos musicais, ou outras habilidades com foco em artesanato e em trabalhos manuais, por exemplo.

Os interesses apresentados nos remetem para as alternativas propostas pelas UNATIs e UNAM que oferecem diversidade em seus programas, abrangendo temas variados, tais como o envelhecimento como processo e as representações sociais do idoso, a música popular brasileira, a dança sênior, a sexualidade na velhice, as oficinas de jogos e de memória, atividades socioculturais, dentre outros. São projetos que cumprem papel importante para a socialização dos idosos, permitindo diálogo, discussão e aquisição de um novo conteúdo que se conecta à experiência de vida dos participantes. Os cursos de idiomas, habilidades para instrumentos musicais ou uso de tecnologias também estão no foco da educação não formal.

O aprendizado de novos idiomas ou de um instrumento musical engendra o desejo do desenvolvimento de novas habilidades na velhice, habilidades estas que irão desafiar um corpo em mudança de suas capacidades psicomotoras e cognitivas. E tal aspecto se mostra interessantemente desafiador ao requerer do aluno e do professor trabalharem com aspectos como as mudanças da velocidade do movimento, ou do processamento cognitivo ou ainda de registro, fixação e evocação de conteúdos ora adquiridos. São processos que ganham potência com o uso das tecnologias digitais e suas linguagens.

No âmbito da educação formal, observa-se o aumento do número de idosos que retornam às salas de aulas para concluir os estudos do ensino fundamental e médio, e aqueles que pela primeira vez terão a oportunidade de ingressar no ensino superior. Nessa perspectiva, reitera-se o ambiente multidisciplinar e intergeracional na EJA ou na universidade, como espaços ricos para trocas e experiências com saberes diversos.

Olhar os anos da maturidade como projetos de vida e recomeços requer uma mudança de paradigma em nossa sociedade, lugares em que os idosos exercem seus direitos à educação e cultura, não somente como consumidores de bens culturais, mas também como produtores culturais. 


\section{Considerações finais}

O envelhecimento populacional vem criando novas demandas sociais em diversos países, somadas àquelas ainda não atendidas em países em desenvolvimento. Ao se falar em velhice é sempre importante ressaltar que, muito embora, eufemismos para designar esse tempo no mundo moderno, tal como "terceira idade" ou "melhor idade" sejam incorporados em uma sociedade de consumo como a nossa, e de fato tenhamos parcelas dessa população alinhadas a essa dinâmica, existe uma velhice excluída, solitária, desempoderada, que não dispõe de recursos para trocas, que não pode executar seus planos de vida e depende de apoio e cuidado. Nesse sentido, estamos sempre a falar de velhices, porque desiguais e heterogêneas.

As políticas públicas sociais, a exemplo da PNI e do Estatuto do Idoso, estabelecem formas em que o Estado e a sociedade se relacionam com a população idosa, emanando diretrizes para as principais áreas que dizem respeito ao universo da cidadania da pessoa idosa. Dentre essas, a educação e a cultura se distinguem nessa reflexão ao buscarmos compreender as relações entre temporalidade, envelhecimento e linguagens tecnológicas e a maneira como os processos de emancipação humana na contemporaneidade se articulam ao domínio e capacidade de comunicar, expressar e produzir linguagem em novas configurações e ambientes da cultura digital. Qual papel tem desempenhado a educação formal e a educação não formal quando se trata da educação de idosos? Em que medida esses espaços têm contribuído para processos de inclusão da população idosa no universo da cultura digital? Qual o potencial da educação entre gerações e o quanto as instituições sociais, educacionais e contextos familiares têm favorecido a intergeracionalidade?

Buscou-se refletir sobre as condições concretas para a inclusão digital diante das profundas desigualdades sociais e distintas condições de acesso das populações que caracterizam o universo de pessoas idosas no país, destacando, todavia, expectativas crescentes em termos de inclusão plena desse grupo etário na sociedade, na cultura e na economia, com qualidade de vida e exercício de direitos, bem como resgate de condições para seu reconhecimento social e relações familiares e sociais significativas. Nessa direção, a potência do trabalho educacional é ressaltada, com destaque para a educação formal, educação não formal e educação informal e suas instituições e ambiências. 
Impõe-se a necessidade de pesquisa e desenvolvimento de estudos com foco no aprendizado de pessoas idosas, considerando-se os declínios cognitivos e funcionais, e a reorganização cerebral, uma vez que novos conteúdos se interconectam às experiências de vida, o que potencializa o aprendizado. O desenvolvimento da temática remete ainda a pensar nos materiais a serem utilizados no ensino de idosos, considerando-se as mudanças sensoriais e motoras advindas do envelhecimento. O conhecimento sobre as tecnologias assistivas e demais equipamentos de apoio, com vistas à otimização da funcionalidade, tais como iluminação, magnificação da imagem, contraste entre figura e fundo, ou ainda considerar o que pode minimizar as perdas auditivas ou cognitivas, como as estratégias compensatórias às perdas funcionais, poderá ser potencializado com o uso de tecnologias digitais. A organização das estratégias de ensino, o tempo de duração das aulas e tarefas, a frequência das aulas e cursos, além do cuidado em relação à altura da voz e velocidade com a qual as informações são faladas, são todas questões importantes a se refletirem nos processos de ensino-aprendizagem.

Os desafios são sempre acompanhados de oportunidades e, nessa perspectiva, a mudança demográfica que se anuncia provoca a capacidade de lidar com situações inéditas, mobilizar recursos diversos, buscando gerar estratégias inclusivas que pavimentam uma estrada que todos devemos percorrer.

\section{Referências}

BEAUVOIR, S. A velhice. Trad. Maria Helena F. Martins. 3.ed. Rio de Janeiro: Nova Fronteira, 2018. [recurso eletrônico].

BRASIL. Lei $n^{\circ} 8.842$, de 4 de janeiro de 1994. Dispõe sobre a Política Nacional do Idoso, cria o Conselho Nacional do Idoso e dá outras providências. Diário Oficial da União, Brasília, 5 jan.1994. Disponível em: http://www.planalto. gov.br/ccivil_03/leis/l8842.htm. Acesso em: 20 jan. 2020.

BRASIL. Lei $n^{\circ} 10.741$, de 1 de outubro de 2003. Dispõe sobre o Estatuto do Idoso e dá outras providências. Diário Oficial da União, 3 out. 2003. Disponível em: http://www.planalto.gov.br/ccivil_03/leis/2003/L10.741.htm. Acesso em: 20 jan. 2020.

CACHIONI, M.; TODARO, M.: Política Nacional do Idoso: reflexões acerca das intenções direcionadas à educação formal. In: ALCÂNTARA, A.; CAMARANO, A.; GIACOMIN, K. (orgs.) Política Nacional do Idoso: novas e velhas questões. Rio de Janeiro: IPEA, 2016, p.175-198. 
CAMARANO, A. Introdução. In: ALCÂNTARA, A.; CAMARANO, A.; GIACOMIN, K. (orgs.) Política Nacional do Idoso: novas e velhas questões. Rio de Janeiro: IPEA, 2016, p.15-47.

FERRIGNO, J. C. O idoso como mestre e aluno das novas gerações. In: ALCÂNTARA, A.;

CAMARANO, A.; GIACOMIN, K. (orgs.) Política Nacional do Idoso: novas e velhas questões. Rio de Janeiro: IPEA, 2016, p.211-223.

FREIRE, P. Pedagogia da autonomia: saberes necessários à prática educativa. 60.ed. Rio de Janeiro/São Paulo: Paz e Terra, 2019.

IBGE. Instituto Brasileiro de Geografia e Estatística. 2019. Disponível em:

https://agenciadenoticias.ibge.gov.br/agencia-sala-de-imprensa/2013-agencia-denoticias/releases/26104-em-2018-expectativa-de-vida-era-de-76-3-anos Acesso em 12 jun. 2020.

MARQUES, D. T.; PACHANE, G. G. Formação de educadores: uma perspectiva de educação de idosos em programas de EJA. Educação e Pesquisa, São Paulo, v.36, n.2, p.475-490, maio/ago. 2010.

MERLEAU-PONTY, M. Fenomenologia da percepção. Trad.: Reginaldo Di Pietro. Rio de Janeiro: Freitas Bastos, 1971.

RAYMUNDO, T. M.; SANTANA, C. Percepção de idosos acerca das novas tecnologias. Inteligência Artificial, v.18, p.12-25, 2015.

SANTANA, C.; BERNARDES, M.; MOLINA, A. Projetos de vida na velhice. Estudos Interdisciplinares sobre o Envelhecimento, Porto Alegre, UFRGS, v.21, n.1, p.171-186, 2016.

WOOLRYCH, R. Ageing and technology: creating environments to support an ageing society (keynote). Gerontechnology, v.15, n.2, p.65-97, 2016.

Recebido em 28 fevereiro 2020.

Aprovado em junho 2020. 